\title{
Validation of a child version of the Three-Factor Eating Questionnaire in a Canadian sample: a psychometric tool for the evaluation of eating behaviour
}

\author{
Jaime-lee Yabsley ${ }^{1,2}$, Katie E Gunnell ${ }^{3}$, Eleanor J Bryant ${ }^{4}$, Vicky Drapeau ${ }^{5}$, David Thivel ${ }^{6}$, \\ Kristi B Adamo ${ }^{2}$ and Jean-Philippe Chaput ${ }^{1,2, *}$ \\ 'Healthy Active Living and Obesity Research Group, Children's Hospital of Eastern Ontario Research Institute, 401 \\ Smyth Road, Ottawa, Canada, K1H 8L1: ${ }^{2}$ School of Human Kinetics, University of Ottawa, Ottawa, Canada: \\ ${ }^{3}$ Department of Psychology, Carleton University, Ottawa, Canada: ${ }^{4}$ Division of Psychology, Faculty of Social \\ Sciences, University of Bradford, Bradford, UK: ${ }^{5}$ Department of Physical Education, Faculty of Education, Université \\ Laval, Quebec City, Canada: 'Laboratory of the Metabolic Adaptations to Exercise under Physiological and \\ Pathological Conditions, Clermont Auvergne University, Clermont-Ferrand, France
}

Submitted 8 June 2018: Final revision received 21 September 2018: Accepted 2 November 2018: First published online 27 December 2018

\begin{abstract}
Objective: To examine score validity and reliability of a child version of the twentyone-item Three-Factor Eating Questionnaire (CTFEQ-R21) in a sample of Canadian children and adolescents and its relationship with BMI $Z$-score and food/taste preferences.

Design: Cross-sectional study.

Setting: School-based.

Participants: Children ( $n$ 158), sixty-three boys (mean age 11.5 (sD 1.6 ) years) and ninety-five girls (11.9 (SD 1.9) years).

Results: Exploratory factor analysis revealed that the CTFEQ-R21 was best represented by four factors with item 17 removed (CFFEQ-R20), representing Cognitive Restraint (CR), Cognitive Uncontrolled Eating (UE 1), External Uncontrolled Eating (UE 2) and Emotional Eating (EE), accounting for $41.2 \%$ of the total common variance with good scale reliability. ANOVA revealed that younger children reported higher UE 1 and CR scores than older children, and boys who reported high UE 1 scores had significantly higher BMI $Z$-scores. Children with high UE 1 scores reported a greater preference for high-protein and -fat foods, and high-fat savoury (HFSA) and high-fat sweet (HFSW) foods. Higher preference for high-protein, -fat and -carbohydrate foods, and HFSA, HFSW and low-fat savoury foods was found in children with high UE 2 scores.

Conclusions: The study suggests that the CFFEQ-R20 can be used to measure eating behaviour traits and associations with BMI $Z$-score and food/taste preferences in Canadian children and adolescents. Future research is needed to examine the validity of the questionnaire in larger samples and other geographical locations, as well as the inclusion of extraneous variables such as parental eating or socio-economic status.
\end{abstract}

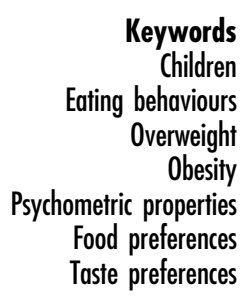

The percentage of Canadian children with overweight and obesity has increased significantly over the past decade ${ }^{(1)}$, with currently one child in seven between the age of 2 and 17 years having obesity ${ }^{(2)}$. Excess weight in children and adolescents is a risk factor for a variety of chronic diseases, including hypertension, type 2 diabetes mellitus, CVD and certain types of cancer $^{(2)}$, and is linked to emotional health issues, low self-esteem ${ }^{(3)}$, stigmatization $^{(4)}$, poor academic performance and lower quality of life in children and adolescents ${ }^{(5)}$, which may increase the risk of presenting altered eating behaviours. Although the health consequences of obesity are well established, obesity is a multifactorial condition with a paucity of successful treatment or prevention strategies ${ }^{(1)}$.

Dietary intake, eating behaviours, appetite and physical inactivity in the paediatric population are linked to the obesogenic environment, which imposes factors that encourage overeating or increased energy intake in the form of energy- and sugar-dense foods, increasing passive overconsumption $^{(6,7)}$. As eating behaviour traits are one factor affecting weight gain, part of the solution to overcoming the high rates of obesity is to understand the link 
between eating behaviour traits and excess weight. Specific eating behaviour traits have been linked to excess weight in children and adolescents ${ }^{(8-10)}$; however, the ability to accurately and conveniently measure these eating behaviour traits, especially in Canada, remains an important understudied research area.

One widely used tool to measure eating behaviour traits is the Three-Factor Eating Questionnaire (TFEQ) developed by Stunkard and Messick ${ }^{(11)}$. The TFEQ is a selfassessment scale based on the Restraint Theory ${ }^{(12)}$ and the Latent Obesity Theory proposed by Meyer and Pudel ${ }^{(13)}$. The TFEQ measures eating behaviour traits in response to social, environmental and emotional factors, such as: (i) Dietary Restraint (restriction of food intake to control weight); (ii) Disinhibition (tendency to overeat opportunistically); and (iii) Hunger (responsiveness to internal and external hunger sensations) ${ }^{(11)}$.

The TFEQ has recently been revised into a psychometrically robust shortened version of the twenty-one-item questionnaire (TFEQ-R21) utilizing the same items as the original TFEQ but assessing slightly different factors: (i) Cognitive Restraint (CR; unchanged); (ii) Uncontrolled Eating (UE; eating in response to food palatability and likelihood of overeating); and (iii) Emotional Eating (EE; eating in response to negative moods ${ }^{(14)}$. The UE and EE subscales of the TFEQ-R21 were shown to have utility in predicting weight gain and weight-loss success in obese and non-obese adult samples, while EE was also found to be associated with overweight and obesity ${ }^{(14)}$. Until recently, research on the utility of the TFEQ has focused on varied adult populations ${ }^{(11,14-20)}$, including university students $^{(15,21-23)}$, participants of weight-loss interventions $^{(24-27)}$ and adolescents ${ }^{(16,28,29)}$.

Associations between $\mathrm{BMI}$ and $\mathrm{CR}^{(9,16,28-34)}, \mathrm{EE}^{(29,35-37)}$ and $\mathrm{UE}^{(8,29,38)}$ currently exist in the literature in children and adolescents. However, the eating behaviour traits measured in these studies were based on the adult TFEQ and not on a TFEQ version that had been developed for children and adolescents. A Spanish version of the TFEQR21 tailored to children and adolescents was recently developed; the subsequent analysis confirmed the threefactor structure and good subscale internal consistency of the questionnaire ${ }^{(10)}$. Furthermore, researchers found that children who scored low on all three subscales of the TFEQ-R21C were found to have lower BMI and weight ${ }^{(10)}$. More recently, an English, child version of the TFEQ-R17 (CTFEQ-R17) has been developed ${ }^{(8)}$ to measure the cognitive and behavioural nature of food intake. The findings ${ }^{(8)}$ supported a three-factor structure, with a good internal consistency ${ }^{(8)}$. That study also found that a higher CR score was associated with a higher weight and BMI, and high UE and EE scores were associated with a preference for high-fat savoury and high-fat sweet foods ${ }^{(8)}$. However, no research to date has reported on the utility or validation of the instrument in Canadian child and adolescent populations. Therefore, the development and validation of a Canadian child version of the questionnaire is needed for paediatric populations to elucidate relationships between eating behaviour traits and weight.

The primary objective of the present study was to validate scores of a child version of the twenty-one-item Three-Factor Eating Questionnaire developed by Bryant and colleagues $(C T F E Q-R 21)^{(8)}$, by examining reliability and validity evidence of CTFEQ-R21 responses in a sample of Canadian children and adolescents. The secondary aim was to examine the associations between the CTFEQ-R21 factors, BMI $Z$-score and food/taste preferences. The examination of the score validity of the CTFEQ-R21 ${ }^{(8)}$ in Canadian children and adolescents was conducted concurrently with Bryant and colleagues ${ }^{(8)}$ in the UK, with the overarching goal of validating responses to the questionnaire. Cappelleri and colleagues have suggested that cultural differences exist in eating behaviour, factor structures and the understanding of questionnaire items ${ }^{(14)}$. Therefore, the present study was conducted concurrently with Bryant and colleagues ${ }^{(8)}$ to increase the external generalizability of the results and validate responses to the questionnaire in Canadian children and adolescents for wider use.

\section{Methods}

\section{Study protocol}

The present study is a cross-sectional, observational study. English Public and English Catholic school boards in the Ottawa area were contacted to determine their interest in taking part. A first-come, first-served approach was utilized when recruiting participants (convenience sample). If the school indicated interest in participating, researchers visited the school to provide information to the teacher and students. Information packages containing an invitation letter, parent information letter, consent form and assent form were sent home with the students for their parents/guardians, inviting their child to participate in the study. The consent and assent forms clearly stated that participation in the study was voluntary and the participant would be allowed to decline participating at any point in the process of the study. After being provided with full details of the study at least one week before data collection, written informed consent was obtained from the parent if $\mathrm{s} /$ he were interested in having her/his child participate. Study coordinators obtained and validated consent forms before the testing date. Children gave their verbal assent and were assured that they could withdraw consent at any point during the process. If a participant did not want to participate in testing, despite her/his parent's consent, s/he could opt out of participating.

\section{Participants}

Information letters and consent/assent form packages were sent to eleven schools in the Ottawa area and a 
convenience sample of 176 children was recruited from seven schools. Four of the interested schools did not have enough children interested in the study and/or the school did not have enough staff to coordinate data collection, and therefore withdrew their participation. The final sample used for analysis was 158, as eighteen students were absent during the time of data collection and did not take part in data collection. Parents and principals noted that low response rates were likely due to parental concerns about having their child weighed at school and concern that it will encourage weight teasing.

\section{Study procedure}

The study was conducted on one single occasion in the classroom at the school. Testing was carried out from October 2016 until May 2017, at approximately the same time of day each time (between 09.00 and 11.00 hours) to reduce the effects of appetite on self-reported eating behaviour traits and food preferences. Participants were asked to self-complete two short questionnaires on eating behaviour traits and food preferences (20-25 min). All participants received verbal and written instructions on how to complete the questionnaires. Once the questionnaires were completed, the researcher measured the participant's height and weight in a separate, private area (3-5 min). The participant remained fully clothed, with socks on.

\section{Measurements}

\section{Questionnaires}

The CTFEQ-R21. The TFEQ-R21 child version (CTFEQ$\mathrm{R} 21)^{(8)}$ is a twenty-one-item questionnaire based on the adult version of the questionnaire ${ }^{(14)}$. Through structured interviews with children and adolescents, Bryant and colleagues $^{(8)}$ developed a modified version of the questionnaire for children and adolescents (CTFEQ-R21). The CTFEQ-R21 contains twenty-one questions, with a 4-point Likert scale for answering items 1-20, and an 8-point numerical rating scale for item $21^{(8)}$. Items $1-16$ are measured on the same 4-point Likert scale of 'totally true'-'totally false', while items 17-21 are measured on three different 4-point Likert scales including 'almost never'-'almost always', 'never'-'at least once a week' and 'only at meal times'-'almost alwayss ${ }^{(8)}$. The CTFEQ-R21 was designed to measure three factors: (i) CR (unchanged; six items); (ii) UE (i.e. eating in response to food palatability and likelihood of overeating; six items); and (iii) EE (i.e. eating in response to negative moods; six items) ${ }^{(8)}$. Responses on each item of the questionnaire were given a score between 1 and 4, items 1-16 were reverse coded ${ }^{(39)}$, and item 21 was coded as follows: $1-2$ as ' 1 ', 3-4 as ' 2 ', 5-6 as ' 3 ' and 7-8 as ' 4 '. After items were coded, domain scores were calculated as a mean of all items within each domain. Higher scores in each domain are indicative of greater $\mathrm{CR}$, $\mathrm{UE}$ or $\mathrm{EE}^{(8)}$.

Food preference questionnaire. An adapted paperbased version of the Leeds Food Preference Questionnaire (LFPQ), originally validated in an adult population $^{(40)}$, has been demonstrated to be suitable for use in children and to predict actual food intake ${ }^{(41)}$. The questionnaire measures the liking, wanting and preference for certain foods that are categorized by low- and high-fat and by sweet and savoury preferences ${ }^{(40)}$. The LFPQ has been shown to differentiate between weight statuses by food preference categories in children ${ }^{(41)}$. The adapted food preference questionnaire ${ }^{(40)}$ consists of a list of thirtytwo common unbranded UK foods; this version of the questionnaire was modified to suit common Canadian foods. Five food items from the original questionnaire ${ }^{(8)}$ were replaced with similar foods to reflect more common Canadian foods (e.g. 'grilled lean lamb cutlet' was modified to 'grilled pork chop'), while the language of thirteen items was modified slightly to suit the Canadian context (e.g. 'lean piece of gammon' was changed to 'piece of bacon'). The participant is asked to note which foods s/he would like to consume at that moment. Responses were then coded as ' 1 ' for each item the participant indicated $\mathrm{s} /$ he would like to consume. The responses were then summed into food and taste preference scores for eight categories: high-protein foods (eight food items); high-fat foods (eight food items); high-carbohydrate foods (eight food items); low-energy foods (eight food items); low-fat savoury foods (LFSA; twelve food items); low-fat sweet foods (LFSW; five food items); high-fat savoury foods (HFSA; eight food items); and high-fat sweet foods (HFSW; seven food items) ${ }^{(8)}$.

\section{Anthropometric measurements}

Weight was assessed using a digital scale (A\&D Medical, Milpitas, CA, USA), recorded to the nearest $0 \cdot 1 \mathrm{~kg}$. Height was measured with a portable stadiometer (SECA, Hamburg, Germany) placed on a flat, level surface, recorded to the nearest $0.1 \mathrm{~cm}$. Two height and weight measurements were taken, and a third measurement was taken in the instance that the first two measurements were more than $0.5 \mathrm{~cm}$ or $0.5 \mathrm{~kg}$ apart. The average of the two closest measures was recorded. BMI was calculated as body weight in kilograms divided by the square of height in metres ${ }^{(42)}$ and then converted to BMI $Z$-score ${ }^{(43)}$ using the WHO BMI-for-age growth charts reference standard ${ }^{(44)}$.

\section{Statistical considerations}

\section{Sample size calculation}

The literature provides little guidance in terms of the appropriate sample size for exploratory factor analysis, although some rules of thumb have been provided, such as including a minimum sample size of 100 participants ${ }^{(45)}$ or five respondents per item $^{(39)}$ or ten to fifteen 
participants per item of the questionnaire ${ }^{(39)}$. Based on the recommendations for factor analysis sample size, and the possibility of attrition and missing data, the intent of the present study was to recruit a sample of 150-200 children and adolescents.

\section{Data analysis}

All statistical analyses were completed using the statistical software package IBM SPSS Statistics for Windows, version 24.0. Data were examined for missing data, multivariate and univariate outliers, and for violations to the assumptions for multivariate analysis through the procedures outlined by Tabachnick and Fidell ${ }^{(46)}$. Participants with incomplete questionnaire data were excluded from the analysis ( $n$ 11). Potential univariate outliers were detected from all variables in the questionnaire data $(n 4)$ and from the regression scores calculated from the exploratory factor analysis ( $n$ 2). Based on the case-by-case analysis, two univariate outliers were removed from the analysis. With the removal of two univariate outliers and eleven participants with missing data, the final sample size was 145 .

Data used in the ANOVA and ANCOVA met the assumptions for multivariate analysis of linearity and homogeneity of variance. The assumptions of the absence of outliers and normality were violated, but disregarded, as the central limit theory posits that with a large sample, sampling distributions can be considered normal and the ANOVA can produce valid results ${ }^{(46)}$.

\section{Primary data analysis}

As suggested by the Standards for Educational and Psychological Testing validity theory and framework ${ }^{(47)}$, validity evidence was examined using evidence based on internal structure, by determining the factor structure. An exploratory, maximum likelihood, analysis was performed to determine the factor structure of the CTFEQ-R21. Based on previous research demonstrating correlations between the eating behaviour factors of the TFEQ-R21 $1^{(8,10,14)}$, oblique rotation (direct oblimin) was used, to account for the a priori hypothesized correlations between factors ${ }^{(39)}$. The initial number of factors to retain was determined using a structured sequence of criteria: the eigenvalue-one criterion (eigenvalue $>1)^{(39)}$, the number of factors identified by the scree plot test ${ }^{(48)}$, the proportion of variance accounted for $(>5 \%)^{(39)}$ and the interpretability criterion. To be considered a meaningful factor that was retained, at least three variables (items) were required to load on the factor (minimum loading of 0.32$)^{(46)}$, and the variables were required to share conceptual meaning and measure the same concept ${ }^{(39,46)}$. Subsequently, an item analysis was carried out to confirm the internal consistency, itemconvergent validity and item-discriminant validity of the CTFEQ-R21. Internal consistency was carried out by performing the Cronbach $\alpha$ test for each factor; a value $\alpha>0.70$ was considered adequate ${ }^{(39,46,47,49,50)}$. The obtained factor structure from the exploratory factor analysis was then examined to obtain factor-based scores (unit-weighting) by summing responses from items loading on to each factor and then taking the average of each factor to transform the domain scores into continuous variables. Factor-based scores were then used in subsequent analyses as dependent variables.

\section{Secondary data analysis}

A two-way factorial ANOVA was conducted to compare the main effects of age (8-11 years, $n$ 86; $12-15$ years, $n$ 59) and sex (boys; girls), and the interaction effect between age and sex, on the questionnaire factor-based scores.

Since there are no clinical cut-offs of eating behaviour trait scores, a median split on CR, UE and EE factor-based scores was used to dichotomize scores on each factor into low and high factor scores, to allow for group comparisons. A two-way factorial ANCOVA, controlling for age, was used to analyse the main effect of sex and eating behaviour trait median split factor-based groupings on anthropometric measures of weight, BMI and BMI $Z$-score. A two-way factorial ANCOVA, controlling for BMI $Z$-score, was used to analyse the main effect of eating behaviour trait median split factor-based scores on food/taste preferences (high-protein, high-carbohydrate, high-fat, lowenergy, HFSA, HFSW, LFSA, LFSW foods).

After conducting all ANOVA and ANCOVA, Cohen's $f^{2(51)}$ based on the partial $\eta^{2}$ was used to determine the effect sizes, in which $f^{2} \geq 0.02$ was considered a small, $f^{2} \geq 0.15$ was considered a medium and $f^{2} \geq 0.35$ was considered a large effect size ${ }^{(46)}$.

\section{Results}

\section{Primary analysis results}

The participants who completed the questionnaires consisted of a sample of 158 children, sixty-three boys (mean age: 11.5 (SD 1.6) years; mean BMI: 23.8 (SD 4.5 ) kg/m² mean BMI Z-score: 0.22 (SD 1.41)) and ninety-five girls (mean age: 11.9 (SD 1.9) years; mean BMI: 24.7 (sD 6.5$) \mathrm{kg} / \mathrm{m}^{2}$; mean BMI $Z$-score: 0.13 (sD 1.20)).

The data met the assumptions for exploratory factor analysis. The Kaiser-Meyer-Olkin measure of sampling adequacy index was 0.778 and Barlett's test of sphericity test was significant, with $\chi^{2}=938.55, P<0.001$; indicating that there was a sufficient proportion of variance within the sample and items were sufficiently correlated for factor analysis. The exploratory, maximum likelihood, analysis with oblique rotation produced six factors with eigenvalues greater than 1, which accounted for $48.4 \%$ of the total common variance. In an examination of the scree plot, three or four main factors were identified. The unrestricted exploratory factor analysis identified four common factors with at least three items loading on each, thereby 
Table 1 Rotated factor structure loading of the twenty-item child version of the Four-Factor Eating Questionnaire (CFFEQ-R20) from the exploratory factor analysis, with a four-factor restriction model

\begin{tabular}{|c|c|c|c|c|c|}
\hline Questionnaire item & $\begin{array}{c}\text { Factor } 1 \\
\text { Uncontrolled } \\
\text { Eating } 1\end{array}$ & $\begin{array}{l}\text { Factor } 2 \\
\text { Cognitive } \\
\text { Restraint }\end{array}$ & $\begin{array}{l}\text { Factor } 3 \\
\text { Emotional } \\
\text { Eating }\end{array}$ & $\begin{array}{c}\text { Factor } 4 \\
\text { Uncontrolled } \\
\text { Eating } 2\end{array}$ & Communality \\
\hline 1. I eat small portions of food to control my weight & -0.061 & $0.622^{*}$ & -0.028 & $-0 \cdot 131$ & 0.430 \\
\hline 2. I start to eat when I feel worried & 0.030 & -0.037 & $-0.517^{*}$ & -0.003 & 0.273 \\
\hline 3. Sometimes when I start eating, it seems I can't stop & $0.590^{*}$ & 0.179 & 0.018 & 0.020 & 0.342 \\
\hline 4. When I am sad, I usually eat too much & 0.031 & 0.020 & $-0.591^{*}$ & 0.092 & 0.328 \\
\hline 5. I don't eat some kinds of food because they can make me fat & 0.052 & $0.634^{*}$ & 0.019 & $0 \cdot 103$ & 0.389 \\
\hline $\begin{array}{l}\text { 6. When I am eating next to someone who is eating, } \\
\text { I also feel like eating }\end{array}$ & 0.017 & 0.078 & $-0 \cdot 167$ & $-0.362^{*}$ & 0.235 \\
\hline 7. When I feel angry, I need to eat & 0.236 & 0.062 & $-0.403^{*}$ & 0.002 & 0.294 \\
\hline $\begin{array}{l}\text { 8. I often get so hungry that I feel like I could eat loads of food } \\
\text { without getting full }\end{array}$ & $0 \cdot 647^{\star}$ & -0.034 & -0.020 & $-0 \cdot 145$ & 0.551 \\
\hline $\begin{array}{l}\text { 9. When I am hungry, I feel like I have to eat all of the food on } \\
\text { my plate in one go, without stopping }\end{array}$ & $0.537^{\star}$ & -0.014 & -0.060 & -0.058 & 0.352 \\
\hline 10. When I feel lonely, I make myself feel better by eating & -0.148 & 0.048 & $-0.736^{\star}$ & -0.117 & 0.581 \\
\hline $\begin{array}{l}\text { 11. I eat less than I want at meal times to stop myself from } \\
\text { putting on weight }\end{array}$ & 0.107 & $0 \cdot 692^{*}$ & 0.007 & -0.081 & 0.499 \\
\hline $\begin{array}{l}\text { 12. When I smell or see my favourite food, I find it hard to } \\
\text { stop myself from eating it, even if l've just finished a meal }\end{array}$ & 0.080 & -0.025 & 0.060 & $-0 \cdot 821^{\star}$ & 0.704 \\
\hline 13. I am always hungry enough to eat at any time & $0.530^{*}$ & $-0 \cdot 156$ & -0.075 & -0.131 & 0.439 \\
\hline 14. If I feel nervous, I try to calm myself down by eating & $-0 \cdot 114$ & 0.088 & $-0.678^{*}$ & -0.067 & 0.494 \\
\hline $\begin{array}{l}\text { 15. When I see something that looks delicious, I get so hungry } \\
\text { that I have to eat it right away }\end{array}$ & $0 \cdot 201$ & 0.065 & -0.059 & $-0.578^{*}$ & 0.543 \\
\hline 16. When I feel really upset, I want to eat & 0.113 & -0.112 & $-0.623^{*}$ & -0.011 & 0.437 \\
\hline 18. How often would you eat less than you wanted to in a meal? & -0.012 & $0.355^{\star}$ & -0.034 & -0.105 & 0.152 \\
\hline 19. Do you eat lots of food even when you are not hungry? & $0.341^{*}$ & 0.016 & -0.159 & -0.073 & 0.219 \\
\hline 20. How often do you feel hungry? & $0 \cdot 737^{*}$ & -0.124 & 0.073 & 0.016 & 0.537 \\
\hline $\begin{array}{l}\text { 21. What types of eater are you on a scale of } 1 \text { to } 8 \text { ? } \\
\text { Where } 1 \text { means 'I eat whatever I want, whenever I want' and } \\
\text { where } 8 \text { means 'I am careful about what I eat to control my } \\
\text { weight' }\end{array}$ & -0.136 & $0.592^{*}$ & -0.011 & 0.236 & 0.449 \\
\hline Explained variance (\%) & 21.47 & $11 \cdot 27$ & 5.53 & 2.97 & - \\
\hline Cumulative variance (\%) & 21.47 & 32.74 & 38.27 & 41.24 & - \\
\hline
\end{tabular}

$N 145$.

*Items loading significantly on to subscales.

suggesting a new four-factor structure (four-factor questionnaire). Two unique factors were also identified (Factors 5 and 6), accounting for $17.06 \%$ of the total variance, but only one item from the questionnaire loaded on to each of the identified factors. Factors 5 and 6, as well as item 17, were removed in further analysis, and the questionnaire was referred to as the twenty-item child version of the Four-Factor Eating Questionnaire (CFFEQ-R20).

Table 1 presents the results from the maximum likelihood, exploratory factor analysis with oblique rotation (direct oblimin), with a four-factor restriction and item 17 removed from the CTFEQ-R21 questionnaire. The test produced four factors, accounting for $41.2 \%$ of the variance, with all items loading significantly on one factor only. As seen in Table 1, the factor of EE was retained as in the original TFEQ-R21 ${ }^{(14)}$ and CTFEQ-R21 ${ }^{(8)}$, with items 2 , $4,7,10,14$ and 16 loading on to Factor 2. The original factor of $\mathrm{CR}^{(8,14)}$ was also retained, with items $1,5,11,18$ and 21 loading on to Factor 3, with the exception of item 17. The original factor of $\mathrm{UE}^{(8,14)}$ was also retained, but items from the original UE factor divided into two factors in the data: Factor 1 (items 3, 8, 9, 13, 19 and 20) and Factor 4 (items 6, 12 and 15) in Table 1. Therefore, Factor 1 was titled UE 1, with items 3, 8, 9, 13, 19 and 20 loading on to the same factor, and Factor 4 was titled UE 2, with items 6,12 and 15 loading on to the same factor. The items in both UE 1 and UE 2 were related to uncontrolled eating; items in UE 1 were conceptually related to cognition and internal hunger sensations (i.e. thinking about food or feeling hungry), whereas the items in UE 2 were conceptually more related to senses and external food cues and stimuli (i.e. seeing or smelling food). Supported by the Externality Theory, UE 1 was termed Internal Uncontrolled Eating and UE 2 was termed External Uncontrolled Eating $^{(52)}$.

The internal reliability analysis revealed that the CFFEQR20 had a Cronbach's $\alpha$ of $0 \cdot 81$, representing adequate/ good internal consistency, with the factors of CR $(\alpha=0.71)$, EE $(\alpha=0.78)$, UE $1 \quad(\alpha=0.78)$ and UE 2 ( $\alpha=0.69$ ) showing similarly acceptable scores. The item analysis revealed that all the factors had adequate to good inter-item correlations for CR $(r=0 \cdot 12-0 \cdot 50)$, EE $(r=0 \cdot 24-$ $0 \cdot 62)$, UE $1(r=0.27-0.48)$ and UE $2(r=0.30-0.57)$, showing that the items within each scale correlated with one another. The corrected item-total correlation values were good for all factors: CR $(r=0 \cdot 30-0 \cdot 50)$, EE $(r=0.43-$ $0 \cdot 60)$, UE $1 \quad(r=0 \cdot 41-0 \cdot 63)$ and UE $2(r=0 \cdot 40-0 \cdot 61)$. Additionally, the strongest correlation of each item was 
found with the scale assigned, meeting the criteria for item-discriminant validity (UE $1: r=0.58-0.78$; UE 2: $r=0.72-0.85$; CR: $r=0.54-0.76$; EE: $r=0 \cdot 62-0 \cdot 76$ ). Furthermore, the correlations between factors UE 1, EE and CR did not exceed $0 \cdot 70(r=-0 \cdot 66-0 \cdot 69)$, except for factors UE 1 and UE $2(r=0 \cdot 58-0 \cdot 92)$. The factor of UE 1 correlated significantly with UE $2(r=0.52, P<0.001)$ and EE $(r=0.27, P<0 \cdot 01)$. The factor of UE 2 correlated significantly with $\mathrm{EE}(r=0.36, P<0.001)$. The factor of CR correlated significantly with $\mathrm{EE}(r=0 \cdot 20, P<0 \cdot 05)$.

The data can also be fit into a three-factor model to allow for comparison with the original CTFEQ-R21 ${ }^{(8,14)}$ currently used to assess eating behaviour traits in adults. The three-factor model is presented in the online supplementary material.

\section{Secondary analysis results}

Relationship between CFFEQ-R2O factors and participant characteristics

Table 2 presents the mean CFFEQ-R20 factor-based scores by age group ( $8-11$ years and $12-15$ years) and sex (boys and girls). The ANOVA revealed that younger children reported higher UE 1 scores $\left(F_{(1,143)}=3.99, P=0.048\right.$, $\left.f^{2}=0.028\right)$ and CR scores $\left(F_{(1,143)}=3.99, \quad P=0.001\right.$, $f^{2}=0.089$; see Table 2). Mean factor scores of UE 2 and EE did not significantly differ between age groups. Mean factor scores did not significantly differ between sexes.

\section{Relationship between CFFEQ-R2O factors and anthropometric measurements}

Table 3 presents the mean anthropometric measurements by high and low CFFEQ-R20 factor-based scores. The ANCOVA revealed that boys who reported high UE 1 had a significantly higher weight $\left(F_{(1,58)}=6.44, \quad P=0 \cdot 014\right.$, $\left.f^{2}=0 \cdot 117 \mathrm{~kg}\right)$, BMI $\left(F_{(1,58)}=5 \cdot 77, P=0 \cdot 020, f^{2}=0.106 \mathrm{~kg} /\right.$ $\left.\mathrm{m}^{2}\right)$ and BMI $Z$-score $\left(F_{(1,58)}=4.45, P=0.039, f^{2}=0.083\right)$ compared with boys who reported low UE 1 . Age was a significant covariate in the analysis of the difference between high UE 1 and low UE 1 scores and weight in boys $(P<0 \cdot 001)$. No significant differences were found between sexes on high and low factor-based scores, and no significant differences were found within sex on high and low factor-based scores of UE 2, CR and EE.

\section{Relationship between CFFEQ-R2O factors and food and taste preferences}

Table 4 presents the mean food and taste preference scores derived from the LFPQ, by high and low CFFEQR20 factor-based scores.

The ANCOVA controlling for BMI $Z$-score showed that the high UE 1 and high UE 2 groups reported a greater preference for high-protein foods compared with the low UE $1\left(F_{(1,147)}=10 \cdot 14, P=0 \cdot 002, f^{2}=0 \cdot 071\right)$ and low UE 2 $\left(F_{(1,147)}=11 \cdot 38, P=0.001, f^{2}=0.079\right)$ groups. The high UE 2 group reported a greater preference for highcarbohydrate foods compared with the low UE 2 group $\left(F_{(1,147)}=15 \cdot 77, P<0 \cdot 001, f^{2}=0 \cdot 110\right)$, whereas the low CR group reported a higher preference for high-carbohydrate foods $\left(F_{(1,147)}=7.98, P=0.005, f^{2}=0.056\right)$ compared with the high CR group. Furthermore, the high UE 1, high UE 2 and low CR groups reported a greater preference for highfat foods compared with the low UE $1\left(F_{(1,147)}=9 \cdot 50\right.$, $\left.P=0.002, f^{2}=0.063\right)$, low UE $2\left(F_{(1,147)}=13.92, P<0.001\right.$, $\left.f^{2}=0.095\right)$ and high CR $\left(F_{(1,147)}=6.97, \quad P=0.009\right.$, $\left.f^{2}=0.053\right)$ groups. BMI was a significant covariate in the analysis of low and high UE $2\left(F_{(1,147)}=4.35, P=0.039\right.$, $\left.f^{2}=0.030\right)$ and $\mathrm{CR}\left(F_{(1,147)}=7 \cdot 60, P=0.041, f^{2}=0.030\right.$; independent variable) and preferences for high-protein, high-carbohydrate and high-fat foods (dependent variables).

The ANCOVA, controlling for BMI $Z$-score, indicated that the high UE 1, high UE 2 and low CR groups reported a greater preference for HFSA and HFSW foods, compared with the low UE 1 (HFSA: $F_{(1,147)}=10 \cdot 61, P=0 \cdot 001$, $f^{2}=0.074 ;$ HFSW: $\left.F_{(1,147)}=7.55, P=0.007, f^{2}=0.048\right)$, low UE 2 (HFSA: $F_{(1,147)}=6.68, P=0.002, f^{2}=0.067$; HFSW: $\left.F_{(1,147)}=14.58, P=0 \cdot 001, f^{2}=0 \cdot 107\right)$ and high CR (HFSA: $\quad F_{(1,147)}=10.33, \quad P=0.002, \quad f^{2}=0.072 ; \quad$ HFSW: $\left.F_{(1,147)}=8 \cdot 25, P=0 \cdot 005, f^{2}=0 \cdot 046\right)$ groups. The high UE 2 group reported a greater preference for LFSA foods

Table 2 Mean factor-based scores on the twenty-item child version of the Four-Factor Eating Questionnaire (CFFEQ-R20) according to age group and sex in the sample of schoolchildren, Ottawa, Canada, October 2016-May 2017

\begin{tabular}{|c|c|c|c|c|c|c|c|c|c|c|c|c|c|c|c|c|}
\hline & \multicolumn{6}{|c|}{$8-11$ years old } & \multicolumn{6}{|c|}{$12-15$ years old } & \multicolumn{4}{|c|}{ All age groups (8-15 years old) } \\
\hline & \multicolumn{2}{|c|}{ Boys (n 42) } & \multicolumn{2}{|c|}{ Girls ( $n$ 44) } & \multicolumn{2}{|c|}{ Total $(n 86)$} & \multicolumn{2}{|c|}{ Boys $(n 16)$} & \multicolumn{2}{|c|}{ Girls ( $n$ 43) } & \multicolumn{2}{|c|}{ Total $(n 59)$} & \multicolumn{2}{|c|}{ Boys ( $n 58)$} & \multicolumn{2}{|c|}{ Girls ( $n$ 87) } \\
\hline & Mean & SD & Mean & SD & Mean & SD & Mean & SD & Mean & SD & Mean & SD & Mean & SD & Mean & SD \\
\hline CR & $2 \cdot 37$ & 0.50 & $2 \cdot 18$ & 0.64 & $2 \cdot 27^{\star}$, & 0.59 & 1.98 & 0.47 & 1.85 & 0.53 & $1 \cdot 89^{*}, \ddagger$ & 0.51 & $2 \cdot 26$ & 0.52 & 2.02 & 0.62 \\
\hline UE 1 & $2 \cdot 25$ & 0.73 & 2.07 & 0.64 & $2 \cdot 16^{*}, \dagger$ & 0.69 & 1.88 & 0.47 & $2 \cdot 01$ & 0.47 & $1.97^{*}, \dagger$ & 0.47 & $2 \cdot 15$ & 0.68 & 2.04 & 0.56 \\
\hline UE 2 & 2.53 & 0.83 & 2.56 & 0.76 & 2.55 & 0.79 & $2 \cdot 19$ & 0.82 & 2.53 & 0.69 & 2.44 & 0.73 & 2.44 & 0.83 & $2 \cdot 54$ & 0.72 \\
\hline EE & 1.72 & 0.54 & 1.57 & 0.52 & 1.64 & 0.54 & 1.54 & 0.61 & 1.47 & 0.43 & 1.49 & 0.48 & 1.67 & 0.56 & 1.52 & 0.48 \\
\hline
\end{tabular}

CR, Cognitive Restraint; UE 1, Uncontrolled Eating 1; UE 2, Uncontrolled Eating 2; EE, Emotional Eating.

$N 145$.

${ }^{\star} P<0.05$.

†Younger children have significantly higher UE 1 score compared with older children $\left(F_{(1,143)}=3.99, P=0.048\right)$.

¥Younger children have significantly higher CR score compared with older children $\left(F_{(1,143)}=3.99, P=0.001\right)$. 


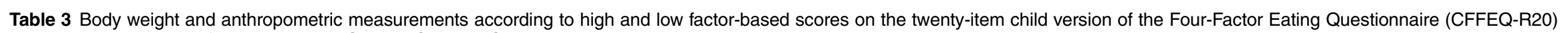
and sex in the sample of schoolchildren, Ottawa, Canada, October 2016-May 2017

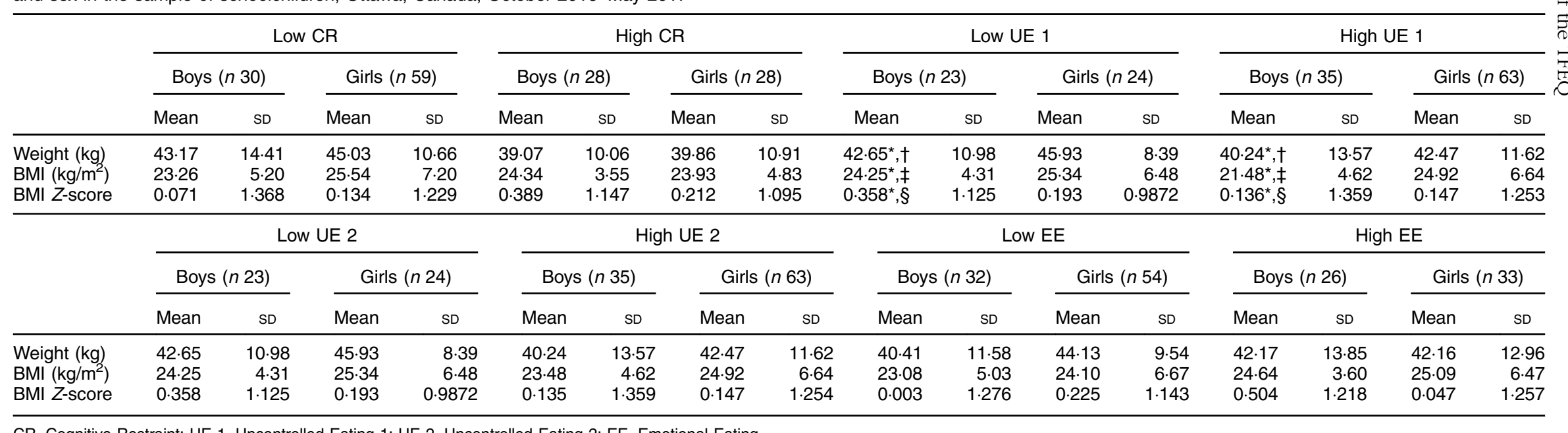

CR, Cognitive Restraint; UE 1, Uncontrolled Eating 1; UE 2, Uncontrolled Eating 2; EE, Emotional Eating.

Age was a significant covariate in the analyses $(P<0.001)$.

$N 145$.

${ }^{\star} P<0.05$.

†Boys in the High UE 1 group had a significantly higher weight compared with those in the low UE 1 group $\left(F_{(1,58)}=6.44, P=0.014\right)$.

fBoys in the High UE 1 group had a significantly higher BMI compared with those in the low UE 1 group $\left(F_{(1,58)}=5.77, P=0.020\right)$.

$\S$ Boys in the High UE 1 group had a significantly higher BMI Z-score compared with those in the low UE 1 group $\left(F_{(1,58)}=4.45, P=0.039\right)$. 
Table 4 Mean food and taste preference scores (Leeds Food Preference Questionnaire) according to high and low factor-based scores on the twenty-item child version of the Four-Factor Eating Questionnaire (CFFEQ-R20) in the sample of schoolchildren, Ottawa, Canada, October 2016-May 2017

\begin{tabular}{|c|c|c|c|c|c|c|c|c|c|c|c|c|c|c|c|c|}
\hline \multirow[b]{2}{*}{ Food/taste preference } & \multicolumn{2}{|c|}{ Low CR ( $n$ 89) } & \multicolumn{2}{|c|}{ High CR ( $n 56)$} & \multicolumn{2}{|c|}{ Low UE 1 ( $n$ 47) } & \multicolumn{2}{|c|}{ High UE 1 ( $n$ 98) } & \multicolumn{2}{|c|}{ Low UE 2 ( $n$ 47) } & \multicolumn{2}{|c|}{ High UE 2 ( $n$ 98) } & \multicolumn{2}{|c|}{ Low EE ( $n$ 88) } & \multicolumn{2}{|c|}{ High EE ( $n$ 57) } \\
\hline & Mean & SD & Mean & SD & Mean & SD & Mean & SD & Mean & SD & Mean & SD & Mean & SD & Mean & SD \\
\hline High-protein foods & 3.32 & $2 \cdot 17$ & $2 \cdot 68$ & $2 \cdot 00$ & $2 \cdot 48^{\star}, \dagger$ & 1.93 & $3 \cdot 58^{*}, \dagger$ & $2 \cdot 16$ & $2 \cdot 26^{\star}, \ddagger$ & 1.91 & $2 \cdot 48^{\star}, \ddagger$ & $2 \cdot 12$ & $2 \cdot 81$ & $2 \cdot 13$ & 3.47 & 2.06 \\
\hline High-carbohydrate foods & $3.98^{*}, \|$ & 1.88 & $3.09^{\star}, \|$ & 1.92 & 3.34 & 1.82 & 3.89 & 2.00 & $2 \cdot 77^{*}, \S$ & 1.88 & $4.05^{\star}, \S$ & 1.83 & 3.65 & 1.92 & 3.63 & 1.97 \\
\hline High-fat foods & $4.09^{*}, \dagger \dagger$ & 2.05 & $3 \cdot 20^{\star}, \dagger \dagger$ & $2 \cdot 01$ & $3 \cdot 19^{\star}, \boldsymbol{\Pi}$ & 2.02 & $34 \cdot 21^{*}, \mathbb{\Upsilon}$ & 2.02 & $2 \cdot 89^{*}, * *$ & 1.90 & $4 \cdot 15^{\star}$, ,** & 2.04 & 3.55 & 2.08 & 4.05 & 2.05 \\
\hline Low-energy foods & 4.69 & 1.89 & 4.61 & 1.84 & 4.84 & 1.88 & 4.51 & 1.85 & 4.57 & 1.67 & 4.70 & 1.86 & 4.65 & 1.76 & 4.68 & 2.02 \\
\hline HFSA foods & 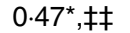 & 0.27 & $0.33^{\star}$,㧊 & 0.25 & $0.34^{*}, \S \S$ & 0.26 & $0.49^{\star}, \S \S$ & 0.26 & $0.32^{\star},\|\|$ & 0.24 & $0.47^{\star},\|\|$ & 0.27 & 0.39 & 0.27 & 0.47 & 0.27 \\
\hline HFSW foods & $0.53^{\star}, \boldsymbol{\uparrow}$, & 0.24 & $0.43^{\star}, \boldsymbol{\uparrow}$ & 0.24 & $0.43^{\star * \star * \star *}$ & 0.25 & $0.54^{\star, * \star \star}$ & 0.02 & $0.38^{\star}, \dagger \dagger \dagger$ & 0.23 & $0.54^{*}, \dagger \dagger \dagger$ & 0.24 & 0.48 & 0.23 & 0.52 & 0.27 \\
\hline LFSA foods & 0.44 & 0.22 & 0.40 & 0.22 & 0.40 & 0.21 & 0.43 & 0.24 & $0.36^{\star}, \ddagger \ddagger \ddagger$ & 0.21 & 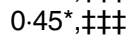 & 0.22 & 0.41 & 0.21 & 0.44 & 0.22 \\
\hline LFSW foods & 0.64 & 0.25 & 0.66 & 0.26 & 0.66 & 0.25 & 0.64 & 0.28 & 0.62 & 0.23 & 0.66 & 0.28 & 0.67 & 0.25 & 0.62 & 0.28 \\
\hline
\end{tabular}

CR, Cognitive Restraint; UE 1, Uncontrolled Eating 1; UE 2, Uncontrolled Eating 2; EE, Emotional Eating; HFSA, high-fat savoury; HFSW, high-fat sweet; LFSA, low-fat savoury; LFSW, low-fat sweet.

BMl was a significant covariate $(P=0.039-0.041)$

Age was a significant covariate in the analyses $(P<0.001)$

$N 145$.

${ }^{\star} P<0.05$.

†The high UE 1 group reported a significantly higher preference for high-protein foods compared with the low UE 1 group $\left(F_{(1,147)}=10.14, P=0.002\right)$

†The high UE 2 group reported significantly higher preference for high-protein foods compared with the low UE 2 group $\left(F_{(1,147)}=11.38, P=0.001\right)$.

SThe high UE 2 group reported significantly higher preference for high-carbohydrate foods compared with the low UE 2 group $\left(F_{(1,147)}=15.77, P<0.001\right)$.

$\|$ The low CR group reported significantly higher preference for high-carbohydrate foods compared with the high CR group $\left(F_{(1,147)}=7.98, P=0.005\right)$.

TThe high UE 1 group reported significantly higher preference for high-fat foods compared with the low UE 1 group $\left(F_{(1,147)}=9 \cdot 50, P=0.002\right)$.

**The high UE 2 group reported significantly higher preference for high-fat foods compared with the low UE 2 group $\left(F_{(1,147)}=13.92, P<0.001\right)$

t†The low CR group reported significantly higher preference for high-fat foods compared with the high CR group $\left(F_{(1,147)}=6.97, P=0.009\right)$.

\#+The low CR group reported significantly higher preference for HFSA foods compared with the high CR group $\left(F_{(1,147)}=10.33, P=0.002\right)$.

SS high 1 .

I The high UE 2 group reported significantly higher preference for HFSA foods, compared to the Low UE 2 group $\left(F_{(1,147)}=6.68, P=0.002\right)$.

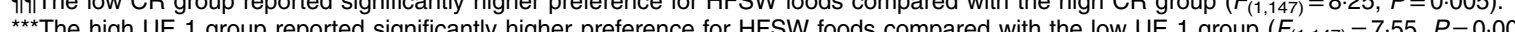

The high 1 .

t+tThe high UE 2 group reported significantly higher preference for LFSA foods compared with the low UE 2 group $\left(F_{(1,147)}=5.67, P=0.019\right)$. 
compared with the low UE 2 group $\left(F_{(1,147)}=5 \cdot 67\right.$, $P=0 \cdot 019, f^{2}=0 \cdot 039$ ).

No significant relationships were found between high and low UE 1, UE 2, CR and EE factor-based scores and low-energy food preference. Additionally, no differences were found between boys and girls or young and older children for low and high factor median split factor-based grouping of food and taste preferences.

\section{Discussion}

Despite the widespread utility of the adult version of the TFEQ, minimal studies have reported validity evidence of TFEQ scores in children ${ }^{(8,10)}$. The primary purpose of the present study was to validate scores from a child version of the TFEQ ${ }^{(8)}$ by examining the validity evidence (factor structure, convergent and discriminant) reliability (internal consistency) of the CTFEQ-R21 in a sample of Canadian children and adolescents. The secondary aim was to examine the associations between the CTFEQ-R21 factors and BMI $Z$-score and food/taste preferences.

\section{Validity of the responses to the child version of the TFEQ}

The current study provided initial validation evidence demonstrating that eating behaviour traits are best categorized into four factors representing CR, UE 1, UE 2 and EE, partially supporting the original factor structure of the TFEQ-R21 ${ }^{(14)}$ and CTFEQ-R21 ${ }^{(8)}$, and the three-factor structure of the Spanish child version ${ }^{(10)}$. The four-factor model (CFFEQ-R20) was considered appropriate for our sample, as it accounted for more variance than the threefactor model, the Cronbach's $\alpha$ values of the individual subscales of UE were adequate and the model was supported by theory ${ }^{(54)}$. The different factor structure observed in the present study highlights the importance of validation research to ensure we are obtaining meaningful results and cross-validation of findings to ensure they are stable across different samples.

A scale must be homogeneous for its scores and results to be interpretable and to provide relevant and useful information $^{(47)}$. The original scale of UE was a heterogeneous construct, with internal and external hunger cues contributing to the overall score. This division of the original UE scale ${ }^{(14)}$ in this sample is supported by Externality Theory, which posits that external eating involves a decrease in internal signals to hunger and satiety and an increase in cues to external eating, which can contribute to overweight or obesity ${ }^{(52)}$. Similar to the division of UE into two factors found in our sample, Bond et al. ${ }^{(15)}$ found the scale of Hunger could be usefully divided into two constructs: Internal Locus of Hunger and External Locus of Hunger. Interestingly, the items comprising the original UE factor of the TFEQ-R21 ${ }^{(14)}$ were composed of both
Disinhibition and Hunger items of the original questionnaire ${ }^{(11)}$ and Karlsson et al. ${ }^{(18)}$ found that the most influential items were the items relating to appetite in participants with obesity. The division of the UE factor allows for the identification of heterogeneous UE concepts, to determine if an increase in weight is influenced by impaired internal satiety signals ${ }^{(53)}$, increased responsiveness to external food cues ${ }^{(54)}$, or a combination of the two constructs.

Our findings showed that item 17 was identified as an item that did not load in the exploratory factor analysis, and items 6, 18 and 19 were items with low communalities and weak loading patterns, which is supported by the findings in adult ${ }^{(14-16,57)}$ and child samples ${ }^{(10)}$. Items 17-20 are measured on three different 4-point Likert scales with reverse anchors, while items 1-16 are measured on the same 4-point Likert scale with different Likert response categories used for items measuring the same construct, which may contribute to the difficulty of the scale for children. It may be valuable to conduct structured interviews in which Canadian children are asked to verbalize the understanding and response to the items ${ }^{(47)}$, as the understanding of the items may vary culturally ${ }^{(14)}$. The weak loading items may be the result of response set bias in the form of social desirability, or response style bias ${ }^{(56,57)}$. Implementing a 5-point Likert scale with a neutral option should also be explored in this questionnaire to mitigate the non-response bias and social desirability response bias ${ }^{(58,59)}$.

The factors of UE 1, UE 2 and CR were positively correlated with $\mathrm{EE}$ in our sample, which is in line with previous research ${ }^{(8,10,16,29)}$ using the TFEQ and the Dutch Eating Behaviour Questionnaire (DEBQ) ${ }^{(10,35,38)}$. These results are also supported by the Externality Theory ${ }^{(52)}$, as an increase in EE, which is a form of disinhibition, may cause a feeling of loss of control which in turn can make an individual more susceptible to external food cues. The positive relationship between UE 1, UE 2 and EE demonstrates that emotionality and external food cues can operate together to elicit eating behaviour, despite being independent constructs ${ }^{(60)}$. The association between CR and EE was consistent with one study, in a sample of adolescents $^{(16)}$, but inconsistent with more recent findings in a sample of children and adolescents ${ }^{(8,10)}$.

\section{CFFEQ-R2O factors and participant characteristics}

The finding that younger children reported higher CR and UE 1 scores was supported by the findings of Bryant et $a l .{ }^{(8)}$, whereas other research has indicated a null finding between age $\operatorname{groups}^{(35)}$. This discrepancy observed in the relationships reported between CR and age may be the result of adolescents under-reporting restraint behaviours, particularly girls ${ }^{(61)}$. The higher scores of UE 1 in younger children demonstrate that they tend to eat more in relation to internal hunger and satiety 
signals, than to external food cues. It has also been found that CR was related to BMI in early adolescence, but later on did not predict any changes in $\mathrm{BMI}^{(62)}$, which also may explain our findings that CR was significantly higher in younger children (age 8-11 years). Although gender differences in $\mathrm{UE}^{(8,16)}$, External Eating ${ }^{(62)}$, $\mathrm{EE}$ and $\mathrm{CR}^{(16,32,36,63)}$ have been observed previously, consistent with the findings of Baños and colleagues ${ }^{(35)}$, mean factor scores did not differ between sexes in our sample. These results from the present study indicate that the CFFEQ-R20 may be influenced by individual characteristics such as age, but not gender.

\section{CFFEQ-R2O factors and anthropometrics}

Our finding that boys reporting higher UE 1 scores had significantly higher weight, BMI and BMI $Z$-score is concordant with previous research ${ }^{(8,29,54)}$; however, it has also been found that lower UE scores were associated with a greater $\mathrm{BMI}^{(10)}$. As higher UE scores have been found to be associated with overweight/obesity in adults $^{(33)}$, it is possible that the association between UE and BMI starts developing in adolescence and increases with age, which is supported by the findings of Snoek and colleagues ${ }^{(62)}$. The lack of relationship between UE 2 and weight outcomes may be the result of the limited number of items within the factor to accurately measure this construct of eating behaviour. Bruch ${ }^{(64)}$ has also suggested that individuals with obesity may not be able to distinguish between internal hunger sensations and other sensations which may stem from parents using food as a reward instead of in response to internal hunger sensations. Furthermore, Baños and colleagues $^{(35)}$ found that the relationship between External Eating and EE, together, explained the higher BMI values. Therefore, it may be useful to examine an aggregate score between UE and EE, and its relationship with BMI.

Contrary to our null findings, CR scores have been found to be linked to a higher BMI in children and adolescents $^{(10,16,28,30-34)}$, especially in girls ${ }^{(8,65)}$. These findings have been explained in terms of the Goal Conflict Theory ${ }^{(66)}$, which states that restrained eaters have an internal conflict between eating food for enjoyment and restricting food intake to control weight. Furthermore, constantly being surrounded by an obesogenic environment makes it more difficult to exercise CR especially when stress and dysphoric moods act as disinhibitors ${ }^{(66)}$. The differences observed in the literature suggest that the relationship between $\mathrm{CR}$ is complex and it may interact with other eating behaviour traits to manifest weight outcomes ${ }^{(9,67)}$. Furthermore, Gallant et al. ${ }^{(9)}$ found that when the CR factor was examined as a whole, there were no differences in BMI $Z$-scores in children and adolescents, but when the CR factor was divided into the Flexible and Rigid Control scales, BMI $Z$-scores were positively related to the Rigid Control scale of the CR factor, suggesting that the Flexible Control scale may have a moderating effect on BMI.

\section{CFFEQ-R2O factors, and food and taste preferences} Children who reported high UE 1 and high UE 2 scores reported greater preference for high-protein and high-fat, and HFSA and HFSW foods; this taste preference pattern associated with high UE 1 and high UE 2 has also been observed in child and adolescent populations ${ }^{(8)}$, showing higher preference for high-carbohydrate and high-fat, and HFSA and HFSW foods. These results are also consistent with findings in adult populations, where it was found that high UE scores were related to more fatty and salty foods ${ }^{(16,68)}$. The main food/taste preference linked to overeating in both girls and boys has also been identified as sweet foods ${ }^{(69)}$, which is also linked to high-fat foods, as sugar has been found to conceal the taste of fat ${ }^{(70)}$. This finding is consistent with the Externality Theory ${ }^{(52)}$, in that an increase in sensitivity to external food cues can lead to overeating; in the current obesogenic environment those external food cues ${ }^{(71,72)}$ are normally related to highly palatable foods, such as foods high in fat, salt and sugar ${ }^{(23,73,74)}$. In fact, Chambers et al. $^{(75)}$ found that girls often overate resulting from low satiating effects of carbohydrates. The consistency between findings in adult samples and children for UE suggests that these food preferences may develop in childhood and persist into adulthood. Research has shown that higher levels of the hunger hormone ghrelin have been associated with a higher preference for fat ${ }^{(76)}$, which may explain the finding that high UE 1 (Internal Uncontrolled Eating) scores were associated with high-fat, HFSA and HFSW preferences. The preference for high-fat and sweet foods observed in those with high UE may be in fact related to $\mathrm{EE}$, as sweet foods and high-fat foods are shown to relieve stress by stimulating opioid release in the brain to protect the body from stress ${ }^{(77)}$.

Our results showed that low CR scores were related to preference for high-fat and high-carbohydrate foods, and HFSA and HFSW foods. Consistent with our results, a higher CR score has also been shown to be negatively correlated with HFSW and HFSA foods in adults ${ }^{(78,79)}$. The variability of the relationship between CR and food preferences may be the result of some individuals having a better ability to maintain $\mathrm{CR}^{(26,53,80)}$.

\section{Limitations, future directions and significance}

While the present study contributes to the current validity evidence for a tool to assess eating behaviour traits in Canadian children and adolescents and assess eating behaviour traits in relation to weight status, it is important to acknowledge the limitations of the study. Due to the small sample size, the use of a convenience sample of children mainly enrolled in public schools and the small 
number of participants with overweight/obesity ( $n$ 8), the results may not be generalizable to all Canadian children, and we cannot rule out sampling bias ${ }^{(81)}$ and the possibility that the children with healthier eating behaviours may have been more inclined to participate in the study. Although relationships between food/taste preferences and anthropometric measures and CFFEQ-R20 were found, actual food intake was not recorded. Another limitation to note is that we did not collect data on ethnicity and socio-economic status, which may act as extraneous variables. Future research should focus on examining the internal structure of the new four-factor model of the questionnaire in a larger sample of Canadian children and adolescents taking into account extraneous variables ${ }^{(82,83)}$, to build more generalizable findings across different populations.

Following further validity and reliability evidence of the questionnaire responses in a larger sample of Canadian children and adolescents, this questionnaire may be used in paediatric populations to better understand how eating behaviour relates to an individual's weight and can aid in the development of future interventions. The knowledge gained from the present study contributes to the current validity evidence informing interventions and may help researchers and clinicians in evaluating the effects of interventions on eating behaviours. The CFFEQ-R20 has the potential to aid in the identification of eating behaviours that may become problematic and contribute to excess weight.

Future research should examine the relationship between offspring and parental eating behaviours using the CFFEQ-R20 and the TFEQ-R21 ${ }^{(14)}$, to provide a more thorough understanding of the eating behaviour traits that are influenced by parental eating patterns. Following the accumulation of more validity and reliability evidence, the questionnaire may be a suitable tool for the comparison between parental and offspring eating behaviours, as it contains the same items as the adult version of the questionnaire (TFEQ-R21) ${ }^{(14)}$.

\section{Conclusion}

In summary, the present study demonstrated evidence of reliability and validity of scores that the CTFEQ-R21 is best represented by a twenty-item four-factor model in our sample. The psychometric analysis revealed that revision of the instrument might increase the validity and reliability. It is also recommended that researchers conduct a psychometric analysis of the questionnaire in their sample before drawing conclusions based on the results. The CFFEQ-R20 was able to identify relevant eating behaviour traits associated with higher BMI $Z$-score in both sexes and age groups. In younger children, food and taste preferences were linked more strongly with the psychological factors of the CFFEQ-R20, whereas food and taste preferences in boys were linked more strongly with anthropometric measures. The process of accumulating validity evidence is ongoing and more evidence to support the four-factor model of the questionnaire is needed before it can be fully implemented as a stable measure of eating behaviour in children and adolescents. It is hoped that this research will stimulate research efforts in this area with a long-term goal of preventing and managing obesity across diverse paediatric populations.

\section{Acknowledgements}

Financial support: This research received no specific grant from any funding agency in the public, commercial por not-for-profit sectors. Conflict of interest: None. Authorship: The authors' responsibilities were as follows. J.Y., K.E.G., E.J.B., V.D., D.T., K.B.A. and J.-P.C. designed the research; J.Y. conducted the research; J.Y. and K.E.G. analysed the data; J.Y. and J.-P.C. wrote the manuscript; and J.-P.C. had primary responsibility for the final content. Ryan Featherstone, a student with the Healthy Active Living and Obesity (HALO) research group at the Children's Hospital of Eastern Ontario Research Institute, also helped with data collection. All authors read and approved the final manuscript. Ethics of human subject participation: This study was conducted according to the guidelines laid down in the Declaration of Helsinki. The Research Ethics Board of the Children's Hospital of Eastern Ontario, the Research Ethics Board of the University of Ottawa and the Ottawa Carleton Research and Evaluation Advisory Committee approved the CTFEQ-R21 validation study. After being provided with full details of the study, written informed consent was obtained from the parent or legal guardian. Children gave their written assent and ongoing verbal assent.

\section{Supplementary material}

To view supplementary material for this article, please visit https://doi.org/10.1017/S136898001800349X

\section{References}

1. Corscadden L, Taylor A, Sebold A et al. (2011) Obesity in Canada: a joint report from the Public Health Agency of Canada and the Canadian Institute for Health Information. https://secure.cihi.ca/free_products/Obesity_in_canada_ 2011_en.pdf (accessed June 2018).

2. Rao DP, Kropac E, Do MT et al. (2016) Childhood overweight and obesity trends in Canada. Health Promot Chronic Dis Prev Can 36, 194-198.

3. Dietz WH (1998) Health consequences of obesity in youth: childhood predictors of adult disease. Pediatrics 101, 518-525.

4. Lobstein T, Baur L \& Uauy R (2004) Obesity in children and young people: a crisis in public health. Obes Rev 5, 4-85. 
5. Sahoo K, Sahoo B, Choudhury AK et al. (2015) Childhood obesity: causes and consequences. J Family Med Prim Care 4, 187-192.

6. Beaulieu K, Hopkins M, Blundell J et al. (2017) Impact of physical activity level and dietary fat content on passive overconsumption of energy in non-obese adults. Int J Behav Nutr Phys Act 14, 14.

7. Blundell JE \& MacDiarmid JI (1997) Fat as a risk factor for overconsumption: satiation, satiety, and patterns of eating. $J$ Am Diet Assoc 97, 7 Suppl., S63-S69.

8. Bryant EJ, Thivel D, Chaput JP et al. (2018) Development and validation of the Child Three-Factor Eating Questionnaire (CTFEQr17). Public Health Nutr 21, 2558-2567.

9. Gallant AR, Tremblay A, Pérusse L et al. (2010) The ThreeFactor Eating Questionnaire and BMI in adolescents: results from the Quebec Family Study. Br J Nutr 104, 1074-1079.

10. Martín-García M, Vila-Maldonado S, Rodríguez-Gómez I et al. (2016) The Spanish version of the Three Factor Eating Questionnaire-R21 for children and adolescents (TFEQR21C): psychometric analysis and relationships with body composition and fitness variables. Physiol Behav 165, 350-357.

11. Stunkard AJ \& Messick S (1985) The three-factor eating questionnaire to measure dietary restraint, disinhibition and hunger. J Psychosom Res 29, 71-83.

12. Polivy J \& Herman CP (1976) Effects of alcohol on eating behavior: influence of mood and perceived intoxication. $J$ Abnorm Psychol 85, 601-606.

13. Meyer JE \& Pudel VE (1977) Experimental feeding in man: a behavioral approach to obesity. Psychosom Med 39, 153-157.

14. Cappelleri JC, Bushmakin AG, Gerber RA et al. (2009) Psychometric analysis of the Three-Factor Eating Questionnaire-R21: results from a large diverse sample of obese and non-obese participants. Int J Obes (Lond) 33, 611-620.

15. Bond MJ, McDowell AJ \& Wilkinson JY (2001) The measurement of dietary restraint, disinhibition and hunger: an examination of the factor structure of the Three Factor Eating Questionnaire (TFEQ). Int $J$ Obes (Lond) 25, 900-906.

16. de Lauzon B, Romon M, Deschamps V et al. (2004) The Three-Factor Eating Questionnaire-R18 is able to distinguish among different eating patterns in a general population. $J$ Nutr 134, 2372-2380.

17. Karaku SŞ, Yıldırım H \& Büyüköztürk Ş (2016) Adaptation of three factor eating questionnaire (TFEQ-R21) into Turkish culture: a validity and reliability study. TAF Prev Med Bull 15, 229-237.

18. Karlsson J, Persson LO, Sjöström L et al. (2000) Psychometric properties and factor structure of the Three-Factor Eating Questionnaire (TFEQ) in obese men and women. Results from the Swedish Obese Subjects (SOS) study. Int J Obes (Lond) 24, 1715-1725.

19. de Medeiros ACQ, Yamamoto ME, Pedrosa LFC et al. (2016) The Brazilian version of the three-factor eating questionnaire-R21: psychometric evaluation and scoring pattern. Eat Weight Disord 22, 169-175.

20. Tholin S, Rasmussen F, Tynelius P et al. (2005) Genetic and environmental influences on eating behavior: the Swedish Young Male Twins Study. Am J Clin Nutr 81, 564-569.

21. Hyland ME, Irvine S H, Thacker C et al. (1989) Psychometric analysis of the Stunkard-Messick Eating Questionnaire (SMEQ) and comparison with the Dutch Eating Behavior Questionnaire (DEBQ). Curr Psychol 8, 228-233.

22. Westenhoefer J (1991) Dietary restraint and disinhibition: is restraint a homogeneous construct? Appetite 16, 45-55.

23. Yeomans MR, Tovey HM, Tinley EM et al. (2004) Effects of manipulated palatability on appetite depend on restraint and disinhibition scores from the Three-Factor Eating Questionnaire. Int J Obes Relat Metab Disord 28, 144-151.
24. Annunziato RA, Lee JN \& Lowe MR (2007) A comparison of weight-control behaviors in African American and Caucasian women. Ethn Dis 11, 418-419.

25. Bryant EJ, Caudwell P, Hopkins ME et al. (2012) Psychomarkers of weight loss. The roles of TFEQ Disinhibition and Restraint in exercise-induced weight management. Appetite 58, 234-241.

26. Keränen AM, Strengell K, Savolainen MJ et al. (2011) Effect of weight loss intervention on the association between eating behaviour measured by TFEQ-18 and dietary intake in adults. Appetite 56, 156-162.

27. Lindroos AK, Lissner L, Mathiassen ME et al. (1997) Dietary intake in relation to restrained eating, disinhibition, and hunger in obese and nonobese Swedish women. Obes Res 5, 175-182.

28. Elfhag K \& Linné Y (2005) Gender differences in associations of eating pathology between mothers and their adolescent offspring. Obes Res Clin Pract 13, 1070-1076.

29. Megalakaki O, Mouveaux M, Hubin-Gayte M et al. (2013) Body image and cognitive restraint are risk factors for obesity in French adolescents. Eat Weight Disord 18, 289-295.

30. Halberstadt J, van Strien T, de Vet E et al. (2016) The association of eating styles with weight change after an intensive combined lifestyle intervention for children and adolescents with severe obesity. Appetite 99, 82-90.

31. Ledoux T, Watson K, Baranowski J et al. (2011) Overeating styles and adiposity among multiethnic youth. Appetite $\mathbf{5 6}$, 71-77.

32. Lluch A, Herbeth B, Mejean L et al. (2000) Dietary intakes, eating style and overweight in the Stanislas Family Study. Int J Obes Relat Metab Disord 24, 1493-1499.

33. Munguía-Lizárraga S, Bacardí-Gascón M, ArmendárizAnguiano A et al. (2015) Association of eating behaviors and BMI among elementary school students from Mexico. Nutr Hosp 31, 2775-2777.

34. Vogels N, Posthumus DL, Mariman EC et al. (2006) Determinants of overweight in a cohort of Dutch children. Am J Clin Nutr 84, 717-724.

35. Baños RM, Cebolla A, Etchemendy E et al. (2011) Validation of the Dutch Eating Behavior Questionnaire for Children (DEBQ-C) for use with Spanish children. Nutr Hosp 26, 890-898.

36. Snoek HM, van Strien T, Janssens JM et al. (2008) Restrained eating and BMI: a longitudinal study among adolescents. Health Psychol 27, 753-759.

37. Van Strien T, Konttinen H, Homberg JR et al. (2016) Emotional eating as a mediator between depression and weight gain. Appetite 100, 216-224.

38. Braet C, Claus L, Goossens L et al. (2008) Differences in eating style between overweight and normal-weight youngsters. J Health Psychol 13, 733-743.

39. Field A (2009) Exploring assumptions, correlation, comparing several means: ANOVA, analysis of covariance, ANCOVA, exploratory factor analysis. In Discovering Statistics Using SPSS, 3rd ed., pp. 131-627. London: SAGE Publications Ltd.

40. Finlayson G, King N \& Blundell JE (2007) Is it possible to dissociate 'liking' and 'wanting' for foods in humans? A novel experimental procedure. Physiol Behav 90, 36-42.

41. Halford JC, Boyland EJ, Cooper GD et al. (2008) Children's food preferences: effects of weight status, food type, branding and television food advertisements (commercials). Pediatr Obes 3, 31-38.

42. Himes JH (2009) Challenges of accurately measuring and using BMI and other indicators of obesity in children. Pediatrics 124, Suppl. 1, S3-S22.

43. Anderson LN, Carsley S, Lebovic G et al. (2017) Misclassification of child body mass index from cut-points 
defined by rounded percentiles instead of Z-scores. BMC Res Notes 10,639.

44. World Health Organization (2007) Growth reference 2-19 years. http://www.who.int/growthref/who2007_bmi_for_ age/en/ (accessed June 2018).

45. Ferguson E \& Cox T (1993) Exploratory factor analysis: a users' guide. Int J Sel Assess 1, 84-94.

46. Tabachnick BG \& Fidell LS (2007) Using Multivariate Statistics, 5th ed., pp. 60-680. Boston, MA: Allyn \& Bacon/ Pearson Education.

47. American Educational Research Association, American Psychological Association \& National Council on Measurement in Education (1999) Validity, reliability/precision and errors of measurement, test design and development, scores, scales, norms, score linking, and cut scores, and test administration, scoring, reporting, and interpretation. In Standards for Educational and Psychological Testing, pp. 23-119. Washington, DC: American Educational Research Association.

48. Cattell RB (1966) The scree test for the number of factors. Multivariate Behav Res 1, 245-276.

49. Bowling A (1997) Data collection methods in quantitative research: questionnaires, interviews and their response rates. In Research Methods in Health: Investigating Health and Health Services, 2nd ed., pp. 257-272. Philadelphia, PA: Open University Press.

50. Cronbach LJ (1951) Coefficient alpha and the internal structure of tests. Psychometrika 16, 297-334.

51. Cohen J (1992) A power primer. Psychol Bull 112, 155-159.

52. Schachter S (1971) Emotion, Obesity, and Crime. New York: Academic Press, Inc.

53. Drapeau V, Provencher V, Lemieux S et al. (2003) Do 6-y changes in eating behaviors predict changes in body weight? Results from the Quebec Family Study. Int J Obes Relat Metab Disord 27, 808-814.

54. Braet C \& Van Strien T (1997) Assessment of emotional, externally induced and restrained eating behaviour in nine to twelve-year-old obese and non-obese children. Behav Res Ther 35, 863-873.

55. de Lauzon-Guillain B, Basdevant A, Romon M et al. (2006) Is restrained eating a risk factor for weight gain in a general population? Am J Clin Nutr 83, 132-138.

56. Paulhus DL (1991) Measurement and control of response bias. In Measures of Social Psychological Attitudes, pp. 17-59 [JP Robinson, PR Shaver and LS Wrightsman, editors]. San Diego, CA: Academic Press.

57. Swain SD, Weathers D \& Niedrich RW (2008) Assessing three sources of misresponse to reversed Likert items. $J$ Mark Res 45, 116-131.

58. Garland R (1991) The mid-point on a rating scale: is it desirable? Mark Bull 2, 66-70.

59. Randall DM, \& Fernandes MF (1991) The social desirability response bias in ethics research. J Bus Ethics 10, 805-817.

60. van Strien T \& Oosterveld P (2008) The children's DEBQ for assessment of restrained, emotional, and external eating in 7 to 12 year old children. Int J Eat Disord 41, 72-81.

61. Babio N, Canals J, Fernández-Ballart J et al. (2008) Nonclinical adolescent girls at risk of eating disorder: underreporters or restrained eaters? Nutr Hosp 23, 27-34.

62. Snoek HM, Engels RC, Van Strien T et al. (2013) Emotional, external and restrained eating behaviour and BMI trajectories in adolescence. Appetite 67, 81-87.

63. Forrester-Knauss C, Perren S \& Alsaker FD (2012) Does body mass index in childhood predict restraint eating in early adolescence? Appetite 59, 921-926.

64. Bruch H (1961) Transformation of oral impulses in eating disorders: a conceptual approach. Psychiatr Q 35, 458-481.
65. Anglé S, Engblom J, Eriksson T et al. (2009) Three factor eating questionnaire-R18 as a measure of cognitive restraint, uncontrolled eating and emotional eating in a sample of young Finnish females. Int J Behav Nutr Phys Act 6, 41.

66. Stroebe W, Van Koningsbruggen GM, Papies EK et al. (2013) Why most dieters fail but some succeed: a goal conflict model of eating behavior. Psychol Rev 120, 110-138.

67. Bryant E J, Kiezerbrink K, King NA et al. (2010) Interaction between disinhibition and restraint: implications for body weight and eating disturbance. Eat Weight Disord 15, e43-e 51.

68. Lähteenmäki L \& Tuorila H (1995) Three-factor eating questionnaire and the use and liking of sweet and fat among dieters. Physiol Behav 57, 81-88.

69. Löffler A, Luck T, Then FS et al. (2015) Age-and genderspecific norms for the German version of the Three-Factor Eating-Questionnaire (TFEQ). Appetite 91, 241-247.

70. Drewnowski A \& Schwartz M (1990) Invisible fats: sensory assessment of sugar/fat mixtures. Appetite 14, 203-217.

71. Anschutz DJ, Engels RC \& Van Strien T (2009) Side effects of television food commercials on concurrent nonadvertised sweet snack food intakes in young children. Am J Clin Nutr 89, 1328-1333.

72. Boyland EJ, Harrold JA, Kirkham TC et al. (2011) Food commercials increase preference for energy-dense foods, particularly in children who watch more television. Pediatrics 128, e93-e100.

73. Swinburn B, Egger G \& Raza F (1999) Dissecting obesogenic environments: the development and application of a framework for identifying and prioritizing environmental interventions for obesity. J Prev Med 29, 563-570.

74. Gerstein DE, Woodward-Lopez G, Evans AE et al. (2004) Clarifying concepts about macronutrients' effects on satiation and satiety. J Am Diet Assoc 104, 1151-1153.

75. Chambers L, McCrickerd K \& Yeomans MR (2015) Optimising foods for satiety. Trends Food Sci Technol 41, 149-160.

76. Akabayashi A, Koenig JI, Watanabe Y et al. (1994) Galanincontaining neurons in the paraventricular nucleus: a neurochemical marker for fat ingestion and body weight gain. Proc Natl Acad Sci U S A 91, 10375-10379.

77. Adam TC \& Epel ES (2007) Stress, eating and the reward system. Physiol Behav 91, 449-458.

78. Elfhag K \& Erlanson-Albertsson C (2006) Sweet and fat taste preference in obesity have different associations with personality and eating behavior. Physiol Behav 88, 61-66.

79. Keskitalo K, Tuorila H, Spector TD et al. (2008) The ThreeFactor Eating Questionnaire, body mass index, and responses to sweet and salty fatty foods: a twin study of genetic and environmental associations. Am J Clin Nutr 88, 263-271.

80. Graham AL, Gluck ME, Votruba B et al. (2014) Perseveration augments the effects of cognitive restraint on ad libitum food intake in adults seeking weight loss. Appetite 82, $78-84$.

81. Severson HH \& Ary DV (1983) Sampling bias due to consent procedures with adolescents. Addict Behav 8, 433-437.

82. Martins C, Morgan L \& Truby H (2008) A review of the effects of exercise on appetite regulation: an obesity perspective. Int J Obes (Lond) 32, 1337-1347.

83. Wardle J, Guthrie C, Sanderson S et al. (2001) Food and activity preferences in children of lean and obese parents. Int J Obes Relat Metab Disord 25, 971-977. 